\title{
O CONCEITO DE ESFERA PÚBLICA JURÍDICA E A AUDIÊNCIA PÚBLICA SOBRE COTAS RACIAIS NO SUPREMO TRIBUNAL FEDERAL ${ }^{1}$
}

\author{
Ricardo Juozepavicius Gonçalves
}

é doutorando e mestre em Filosofia e Teoria Geral do Direito pela Faculdade de Direito da

Universidade de São Paulo (USP). São Paulo, SP, Brasil. E-mail: <ricardojg@usp.br>

http://dx.doi.org/10.1590/0102-135166/103

\section{Introdução}

A partir do advento da Constituição Federal de 1988, iniciou-se no Brasil um período de aprofundamento democrático mediante o aumento de participação social em diversas instituições. O Judiciário, apesar de ser considerado um espaço reservado aos especialistas e técnicos em direito, também foi alvo desse movimento ${ }^{2}$. Novas modalidades de participação social foram praticadas neste período para enfrentar as limitações das formas jurídicas diante de questões sociais complexas e do tradicional déficit democrático dessa instituição.

\footnotetext{
1 Este artigo é resultado parcial dos temas trabalhados na dissertação de mestrado intitulada $O$ conceito de esfera pública jurídica entre Jürgen Habermas e Axel Honneth (Gonçalves, 2017).

2 Conforme José Rodrigo Rodriguez: "com o processo de redemocratização do país, seguiu-se um intenso processo de reivindicação de direitos pela sociedade perante o Poder Judiciário com o fim de tornar efetivas as normas constitucionais. A assim denominada 'constituição cidadã', que nasceu de um intenso processo de debate na sociedade civil com ampla participação popular em sua confecção, tornou-se referência necessária para a luta dos diversos movimentos sociais" (2013a, p. 104).
} 
Uma das formas de conectar o Judiciário com a sociedade tem sido a utilização do instrumento jurídico das audiências públicas no âmbito do Supremo Tribunal Federal (STF). Nestes procedimentos, representantes da sociedade civil envolvidos nas demandas por direitos podem sustentar seus argumentos e posicionamentos sobre o caso discutido.

Analisaremos este recente espaço de deliberação no STF, observando suas características e potenciais democráticos para possibilitar uma maior conexão entre a instituição e os pleitos da sociedade através das regras do Estado Democrático de Direito. Conduzimos nossas observações para a experiência da audiência pública que ocorreu no âmbito da Arguição de Descumprimento de Preceito Fundamental (ADPF) no 186, sobre políticas afirmativas de ingresso no ensino superior realizada em 2010, prática que foi julgada constitucional pela Corte na oportunidade.

Para tanto, analisamos brevemente a argumentação utilizada na audiência pública pelos representantes dos movimentos sociais e da sociedade civil que tiveram espaço e voz na Corte mais alta do Judiciário, levando suas experiências e este pleito dos movimentos sociais até lá, visando influenciar e subsidiar a decisão final.

A ADPF $\mathrm{n}^{\circ} 186$ é um caso exemplar para observarmos o funcionamento da audiência pública judicial, por tratar de um tema de grande repercussão e participação de diversos atores, dentre eles importantes movimentos sociais, os quais discutiram questões estruturantes da sociedade brasileira que levaram à tematização de experiências de desrespeito, argumentos de reconhecimento, de redistribuição ${ }^{3}$ e

\footnotetext{
3 Reconhecimento e redistribuição constituem tema polêmico no âmbito da teoria crítica, principalmente com o debate entre Nancy Fraser e Axel Honneth (2003). Por meio deste debate também é possível traçar outras possibilidades de estudos sobre os diferentes tipos de pleitos sociais e de argumentações e suas recepções no âmbito de uma audiência pública jurisdicional.
} 
à discussão de que as desigualdades sociais estariam conectadas com a existência de um racismo estrutural no Brasil.

Para compreender o espaço e a argumentação que lá ocorre, delimitamos na teoria social de Habermas o conceito de esfera pública jurídica capaz de explicar o significado e a dinâmica dessa participação social numa instituição jurídica aberta à tal prática. Esse conceito possui potencial para compreender um dos momentos em que um pleito social é capaz de invadir o Judiciário, bem como o potencial influenciador desses argumentos em fortalecer a ligação entre as instituições e a sociedade. Contudo, quais são as principais características desta ligação? Em que medida o procedimento é realmente democrático? Os argumentos e pleitos sociais tematizados nas audiências públicas são capazes de influenciar as decisões da Corte?

O diagnóstico que permeia este trabalho expõe que nas últimas duas décadas houve uma mudança de consciência sobre o potencial do direito e do direcionamento das lutas sociais pela efetivação de seus pleitos ${ }^{4}$ ao buscar igualdade pelo reconhecimento das diferenças de indivíduos e de grupos, que é justamente o fator que os coloca em posição subalterna. Conforme afirma Boaventura de Sousa Santos:

Longe de se limitarem a chorar na inércia, as vítimas deste crescente processo de diferenciação e exclusão cada vez mais reclamam, individual e coletivamente, [para] serem ouvidas e organizam-se para resistir. Esta consciência de direitos, por sua vez, é uma consciência complexa, por um lado, compreende tanto o direito à igualdade quanto o direito à diferença (étnica, cultural, de gênero, de orientação sexual, entre outras); por outro lado, reivindica o reconhecimento não só de direitos individuais, mas também

\footnotetext{
4 Além de permear a obra de Boaventura de Sousa Santos (2003, 2011), diagnóstico semelhante também pode ser encontrado em Leonardo Avritzer e Sérgio Costa (2004, pp. 708-710), neste último (Costa, 1994, pp. 42-48), em José Rodrigo Rodriguez (2006, pp. 156-174) e em Rúrion Melo (2015).
} 
de direitos coletivos (dos camponeses sem terra, dos povos indígenas, dos afrodescendentes, das comunidades quilombolas etc.). É essa nova consciência de direitos e a sua complexidade que torna o atual momento sócio-jurídico tão estimulante quanto exigente (Santos, 2011, p. 9).

Além dessa mudança de consciência sobre o potencial do direito, esses atores sociais também passam gradativamente a observar o direito como uma opção efetiva de captação e de resposta às suas lutas, utilizando suas funções, símbolos e dando novos sentidos a essas lutas conduzidas em arenas institucionais:

É possível utilizar instrumentos hegemônicos para fins não hegemônicos sempre e quando a ambiguidade conceptual que é própria de tais instrumentos seja mobilizada por grupos sociais para dar credibilidade a concepções alternativas que aproveitem as brechas e as contradições do sistema jurídico e judiciário (Santos, 2011, p. 22).

Com a elaboração da construção teórica, apresentamos uma interpretação de que tanto as lutas de grupos sociais para inserir seus pleitos no Judiciário quanto o papel das audiências públicas como captadoras desses pleitos consistem em uma possibilidade de aprofundar a conexão entre centros decisórios e problemas sociais complexos. Apesar de toda a construção teórica, o centro deste trabalho se encontra nas demandas sociais e nos atores que tematizam suas experiências de injustiça e que buscam, da forma que têm alcance, conectar as instituições decisórias com a realidade social, buscando uma vida mais justa e igualitária.

\section{0 conceito de esfera pública jurídica}

$\mathrm{Na}$ teoria social habermasiana, o conceito de esfera pública se destaca. Desde que começa a tratar do tema, 
Habermas coloca nele um viés político em seus escritos, elaborando sua teoria social da ação comunicativa nos anos 1980, tornando-o categoria central de sua teoria política da democracia deliberativa na década seguinte.

Em uma perspectiva inicial, a obra Mudança estrutural da esfera pública estabelece o que é público em oposição ao que é privado, tomando o primeiro como um espaço para o uso público da razão, baseado na igualdade entre os indivíduos, ampliando as questões discutidas e possibilitando a participação social na tematização de novas questões por meio de um processo racional de discussão (Lubenow, 2012, p. 16).

A esfera pública pode ser compreendida como uma estrutura de comunicação que permite elaborar temas, questões e problemas politicamente relevantes emergentes da esfera privada e informal da sociedade civil que não possuiriam intervenções "reificantes". O conceito é apresentado como um conjunto de fluxos comunicativos de horizontes abertos, permeáveis e deslocáveis, adequados à disseminação de conteúdos, opiniões e tomadas de posição entre públicos amplos e dispersos.

Na esfera pública, os fluxos comunicativos são filtrados e sintetizados a ponto de se condensar em opiniões públicas, validando uma tomada de decisões que atinge toda a coletividade. É o espaço onde as pessoas são capazes de discutir fundamentos da vida pública e social, permitindo à sociedade influenciar os centros decisórios.

A categoria da esfera pública passou por diversas mudanças teóricas desde sua ideia inicial, dos anos 1960, e a produção habermasiana dos anos 1990. O momento da transição e configuração teórica que nos embasa se encontra no prefácio à edição de Mudança estrutural da esfera pública de 1990. Habermas reformula o conceito, reposicionando-o em um contexto teórico mais amplo que guie sua teoria política de democracia deliberativa, em que o direito terá papel fundamental. 
Em Facticidade e validade, Habermas toma a ideia do Estado Democrático de Direito como o alvo de suas críticas, dado que as instituições jurídico-democráticas possuem uma posição central na caracterização das possibilidades e bloqueios ao aproveitamento dos potenciais comunicativos liberados na modernidade. O modelo crítico desta obra possui uma nova compreensão da emancipação social, pautada nas condições necessárias a um entendimento livre de coerções e um núcleo considerado normativo centrado nas pretensões radical-democráticas de auto-organização de uma comunidade jurídica, a qual expressa a expectativa de uma regulação autônoma da vida social por meio de procedimentos deliberativo-decisórios que podem ser considerados radicalmente inclusivos (Silva, 2011, p. 316).

A distinção dual da sociedade - entre sistema e mundo da vida - também é fundamental na compreensão da concepção habermasiana mais recente de esfera pública. O sis140 tema corresponde ao domínio da vida social em que ocorre a "reprodução material da sociedade", que exige atividades racionais estratégicas e instrumentais pautadas na coordenação dos indivíduos para atingir determinada finalidade calculada. Já o mundo da vida é o espaço informal orientado pelas atividades racionais comunicativas, ou seja, o âmbito da vida social no qual se desenvolvem formas de interação baseadas no entendimento comunicativo, que se reproduz baseado em significados universais atribuídos previamente aos falantes.

O modelo das eclusas, diferentemente do modelo

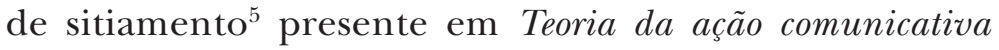
(Habermas, 1984) que norteia as produções anteriores aos anos 1990, revela a possibilidade de uma abertura nos centros sistêmicos relacionada e permitida por uma esfera pública capaz de captar influxos sociais. Trata-se de uma

\footnotetext{
5 Neste modelo, o autor considera que a esfera pública pode apenas "sitiar" o sistema, objetivando conter seus avanços, possuindo uma função predominantemente passiva.
} 
esfera pública sensível e permeável capaz de infiltrar, nos sistemas político, jurídico e administrativo, os conflitos existentes na vida social (Repa, 2008, p. 69). Este modelo se ancora em um conceito amplo de democracia procedimental e deliberativa intimamente conectado aos processos iniciados pela formação da opinião e da vontade nas esferas públicas informais, que acaba infiltrando, de modo procedimental, as instâncias formais de deliberação e decisão.

Os processos jurídico-democráticos alimentam a expectativa de transformar o poder comunicativo, gerado nas bases sociais do mundo da vida em imperativos eficazes frente não apenas a seus destinatários, como também aos sistemas econômico e político. Evidenciam também a possibilidade de inverter o fluxo de poder na direção não habitual da periferia ao centro sistêmico, por meio das diferentes estruturas comunicativas presentes na sociedade civil orientadas aos centros decisórios:

Os fluxos comunicativos que são gerados nas esferas públicas informais da sociedade civil buscam formar uma opinião pública a respeito de algum problema ou polêmica levantada ainda no nível da periferia. Graças às eclusas dos procedimentos próprios à democracia e ao Estado de direito, aquela opinião pública pode tentar lutar por influência política e buscar interferir no comportamento eleitoral das pessoas, na formação da vontade dos complexos parlamentares, governos e tribunais. Assim, a ligação do direito com o poder político permite que a formação de um direito legítimo abra o núcleo sistêmico do poder administrativo aos fluxos comunicativos advindos da periferia (Neves e Lubenow, 2008, p. 254).

Com a iniciativa de atores que os lançam em fóruns públicos informais, os fluxos comunicativos podem ser devidamente elaborados, condensados na forma de temas e 
posições firmadas a seu respeito e dramatizados como questões de relevância pública, tendo a chance de influenciar os centros decisórios e transformar a agenda oficial de problemas (Silva, 2011, p. 322).

As contribuições da esfera pública se chocam com o pano de fundo de saberes especializados pressupostos no funcionamento habitual das instituições jurídico-decisórias, saberes estes que caracterizam as questões sociais levadas a tais contribuições segundo formas paradigmáticas de sua interpretação. Contudo, uma esfera pública jurídica que não limita a argumentação em torno de um tema, pode não obter um enquadramento dogmático já padronizado, ao menos acerca do conteúdo a ser tematizado.

Diante da reconstrução teórica habermasiana apresentada, delimitamos um conceito de esfera pública jurídica no interior da teoria dual de sociedade de Habermas, cuja característica central é ser um espaço propício à formação 142 da opinião e da vontade de um público, porém no contexto de discussões sobre direitos dentro das instituições jurídicas.

A esfera pública jurídica se localiza na fronteira entre sistema e mundo da vida, ou seja, na "periferia sistêmica", área de encontro entre os dois campos do social, considerados por Habermas como desacoplados nas sociedades modernas, embora tais conexões se revistam de um caráter procedimental próprio e necessitem inevitavelmente de institucionalização para que sejam jurídicas:

Tão logo tratamos de um problema como problema jurídico, trazemos imediatamente à baila um conceito de direito moderno que nos obriga - ao menos por razões conceituais - a operar com a arquitetônica do Estado de direito, ela mesma muito rica em pressupostos. Isso também traz consequências para o tratamento do problema da igualação jurídica e do igual reconhecimento de grupos culturalmente definidos, ou seja, de coletividades que se 
distinguem de outras - seja pela tradição, forma de vida, proveniência étnica etc. (Habermas, 2002, p. 243).

A esfera pública jurídica pode ser entendida como a fronteira entre as instituições jurídicas e a sociedade. Este espaço possui maior sensibilidade aos novos e urgentes problemas sociais, podendo captá-los e identificá-los antes das instituições centrais. Uma das formas desta inserção de energia social nas instituições formais se daria mediante pleitos de grupos sociais por direitos, que encontrariam neste espaço um canal para influenciar as decisões e alterar a realidade social conforme suas demandas.

Essa ideia discursiva de democracia que acompanha o conceito se baseia na mobilização política e no aproveitamento da força produtiva da comunicação, sendo que o esclarecimento de questões políticas, no que diz respeito ao seu cerne moral, depende da institucionalização de uma prática de argumentação pública:

O direito é aplicado uma vez mais sobre si mesmo: ele ainda precisa assegurar o modo discursivo segundo o qual os programas jurídicos devem ser criados e aplicados sob as condições da argumentação. Isso implica a institucionalização de procedimentos jurídicos que garantam um cumprimento aproximado dos exigentes pressupostos da comunicação nas negociações equitativas e nas argumentações sem coerção (Habermas, 2014, p. 76).

Em Mudança estrutural da esfera pública, esta conexão entre sociedade e Estado se referia ao uso da razão das pessoas privadas reunidas em um espaço público; já nas produções mais recentes de Habermas, repousa na "institucionalização dos processos comunicativos do mundo da vida nas estruturas jurídicas do Estado democrático de direito" (Voirol, 2008, p. 41). 
Segundo esta concepção, o funcionamento do sistema administrativo possui autonomia em relação aos processos comunicativos; apesar disso, seu funcionamento também deve ser submetido às redefinições propostas por tais processos manifestados no mundo da vida. Assim, uma esfera pública jurídica existente, ativa e aberta, pode pressionar processos jurídico-democráticos para afastar ou frear a ação colonizadora dos sistemas político, econômico e administrativo:

Basta tornar plausível que os atores da sociedade civil, até agora negligenciados, podem assumir um papel surpreendentemente ativo e pleno de consequências, quando tomam consciência da situação de crise. Com efeito, apesar da diminuta complexidade organizacional, da fraca capacidade de ação e das desvantagens estruturais, eles têm a chance de inverter a direção do fluxo convencional da comunicação na esfera pública e no sistema político, transformando destarte o modo de solucionar problemas de todo o sistema político (Habermas, 1997, v. 2, p. 115).

O direito seria capaz de influenciar os subsistemas colonizadores, conforme Habermas: "O peso e abrangência do aparelho do Estado dependem da medida em que a sociedade se serve do medium do direito para influir conscientemente em seus processos de reprodução" (1997, v. 1, p. 171). O modo como a sociedade utiliza o medium do direito está diretamente conectado à existência, abrangência e amplitude de uma esfera pública jurídica, ou seja, de um Judiciário "poroso", que permita tematizações dentro de uma ideia democrática procedimental:

O paradigma jurídico procedimental procura proteger, sobretudo, as condições do procedimento democrático. Elas adquirem um estatuto que permite analisar, sob outra luz, os diferentes tipos de conflito. Os lugares antes ocupados 
pelo participante privado do mercado e pelo cliente das burocracias do Estado de bem-estar social são assumidos por cidadãos que participam de discursos públicos, articulando e fazendo valer interesses feridos, e colaboram na formação de critérios para o tratamento diferenciado de casos diferentes. [...] O fardo desta legitimação suplementar poderia ser assumido pela obrigação de apresentar justificações perante um fórum judiciário crítico. Isso seria possível através da institucionalização de uma esfera pública jurídica capaz de ultrapassar a atual cultura de especialistas e suficientemente sensível para transformar as decisões problemáticas em foco de controvérsias públicas (Habermas, 1997, v. 2, pp. 183-184).

A sociedade civil pode emanar opiniões públicas próprias capazes de influenciar, por exemplo, o Legislativo, obrigando o sistema político a modificar o rumo do poder oficial. Porém, apesar dos agrupamentos da sociedade civil possuírem maior sensibilidade para os problemas sociais, seus pleitos e seus impulsos por mudanças são, normalmente, "muito fracos para despertar a curto prazo processos de aprendizagem no sistema político ou para reorientar processos de decisão" (Habermas, 1997, v. 2, p. 107). Portanto, os grupos sociais e os sujeitos necessitam de uma estrutura mediadora entre seus pleitos e as instituições, amplificando-os e traduzindo-os para que infiltrem os centros decisórios. Esta seria a função e o potencial emancipatório de uma esfera pública jurídica em Habermas.

Porém, o direito, na teoria de Habermas, possui uma ambiguidade inerente (Silva, 2013). Apesar de possuir potencial transformador das relações entre sistema e mundo da vida, também atua como colonizador:

De um lado, ele é a voz da administração e do sistema, em que norma e sanção são inseparáveis uma da outra, ou 
seja, em que o direito aparece como coerção, ainda que coerção legítima. De outro lado, o direito é expressão, simultaneamente, de um processo de formação coletiva da opinião e da vontade, sem o qual seria apenas um estabilizador de expectativas de comportamento e não a expressão da autocompreensão e da autodeterminação de uma comunidade de pessoas de direito que ele também é (Nobre, 2008, p. 27).

A reformulação teórica do autor, no que tange à nova dinâmica de comunicação entre sistema e mundo da vida, recebe inúmeros questionamentos sobre a idealização de seu modelo de esfera pública, em particular a respeito de um de seus pressupostos, o da possibilidade equânime de todas e todos participarem de uma deliberação coletiva. A simples observação de uma situação comunicativa na vida social demonstra:

a desigual participação em uma deliberação, o desequilíbrio na expressão dos pontos de vista, os processos de imposição das opiniões, a recusa do acesso à esfera de discussão, a dominação linguística ou ainda a posse desigual dos recursos simbólicos indispensáveis para a argumentação pública. Tais constatações invalidariam, segundo os críticos, o modelo de esfera pública. Habermas responde a esses argumentos dizendo que o princípio de publicidade seria uma ficção política e que, mesmo se restam dúvidas quanto à sua realização efetiva, o princípio orienta as práticas sociais e inspira as reivindicações políticas e, desse modo, moldou e continua a moldar a instituição da esfera pública (Voirol, 2008, p. 43).

Neste sentido, as audiências públicas podem ser consideradas como uma associação formadora da opinião, em torno da qual pode se cristalizar uma esfera pública jurídica. Essa associação se forma no interior do Estado democrático de direito, e deve garantir a participação e argumentação 
de acordo com seus pressupostos, evitando ao máximo as desigualdades de participação sob pena de não cumprir seu fundamento de existência.

A esfera pública jurídica seria um espaço de conexão direta das instituições jurídicas com a sociedade civil no centro sistêmico, uma área de encontro em que ocorrem trocas entre o sistema e o mundo da vida - considerados por Habermas como tradicionalmente desacoplados. Essas trocas ocorreriam pelas lutas sociais que visam inserir seus pleitos no campo do direito.

\section{As audiências públicas no Supremo Tribunal Federal}

A realização da primeira audiência pública no STF ocorreu em 20 de abril de 2007. Pela primeira vez em mais de 180 anos de história, a Corte mais alta do Judiciário brasileiro abriu suas portas e seus microfones e convidou a sociedade civil para o debate, reunindo mais de vinte especialistas e representantes de setores sociais interessados na constitucionalidade de pesquisas científicas com células-tronco embrionárias $^{6}$ (Marona e Rocha, 2014, pp. 56-57).

A convocação de uma audiência pública no âmbito das ações de competência exclusiva do STF remete à publicação da Lei $\mathrm{n}^{\circ}$ 9.868/99, que dispõe sobre o processo e julgamento da Ação Direta de Inconstitucionalidade (ADI) e da Ação Declaratória de Constitucionalidade (ADC) perante o órgão, e em seu art. $9^{\circ}, \S^{\circ} \stackrel{\circ}{ }$, possibilita ao presidente da Corte, ou ao ministro relator das ações de caráter objetivo, convocar audiências públicas para contribuir com os ministros/as em seu julgamento. Também há tal previsão na Lei $\mathrm{n}^{\mathrm{o}} 9.882 / 99$, que dispõe sobre o processo e julgamento da ADPF em seu art. $6^{\circ}, \S 1^{\circ}$. Em 2009, o procedimento das audiências públicas foi regulamentado no próprio

6 Na ADI no 3510, que impugnava dispositivos da Lei de Biossegurança (Lei $\left.\mathrm{n}^{\mathrm{o}} 11.105 / 2005\right)$. 
Regimento Interno do STF, em seu art. 13, incisos XVII e XVIII, art. 21, incisos XVII e XVIII, e art. 154, este último dispondo sobre o procedimento das audiências públicas.

Apesar do tema estar disciplinado há quase 18 anos, o instrumento foi utilizado em poucas oportunidades: a partir da primeira experiência em 2007 até o segundo semestre de 2017, contam-se 21 audiências públicas sobre os mais diversos temas de repercussão geral e de interesse público ${ }^{7}$, direcionadas ao STF em ações de controle de constitucionalidade, intensificando o uso deste mecanismo institucional ao longo dos anos. Como afirma José Rodrigo Rodriguez:

há mecanismos novos que começam a promover a participação popular no processo decisório, por exemplo, as audiências públicas e o oferecimento de amicus curiae. Ainda que estes mecanismos de participação direta sejam incipientes, por meio deles pode-se ampliar a quantidade de opiniões que influem sobre a decisão final, garantindo-se que a votação que culmina na decisão não resulte apenas da opinião de um pequeno grupo de pessoas (Rodriguez, 2013a, p. 109).

As questões que envolvem a realização das audiências públicas não são complexas apenas juridicamente: tratam de temas polêmicos das mais diversas áreas de conhecimento, que impactam profundamente a sociedade brasileira, como as pesquisas com células-tronco embrionárias e a possibilidade de aborto em caso de fetos anencéfalos, questões estas que envolvem o debate em torno do direito à vida e que se encontram em meio às lutas contemporâneas do movimento feminista global.

Outro exemplo da complexidade de temas é a discussão sobre a política de ações afirmativas para ingresso no ensino

\footnotetext{
7 A lista completa dos temas tratados nas audiências públicas realizadas até o momento no STF está disponível em <https://goo.gl/Pg4LDQ>. Acesso em: 28 mar. 2018.
} 
superior, em que foram levantados argumentos relativos à igualdade material, desigualdades sociais, racismo, genética, história do Brasil, escravidão, entre outros. Além disso, questões ambientais e do sistema de saúde pública também já foram pautas de audiências públicas.

A audiência pública jurisdicional consiste na participação da sociedade civil no julgamento de questões de grande repercussão submetidas ao STF em um feito específico. É um instrumento jurídico que se insere dentro da ideia política da democracia deliberativa e participativa, visando promover um debate aberto e plural e enfrentar dois déficits tradicionais e permanentes da jurisdição constitucional: o da falta de legitimação democrática e de expertise científica para temas complexos. Nos encontros das audiências públicas, os/as ministros/as do STF presentes assumem o papel de ouvintes, enquanto os protagonistas são representantes da sociedade civil e de órgãos do governo relacionados à demanda, especialistas nos temas debatidos e atores diretamente envolvidos com o caso.

Em geral, as audiências públicas iniciam com uma fala de abertura do relator, que passa a palavra para o representante do Ministério Público apresentar suas considerações. Em seguida, os expositores se manifestam de acordo com a ordem previamente estabelecida pelo relator. Do modo como vêm sendo praticadas pelo STF, as audiências públicas ainda variam em relação ao seu formato - considerando a ampla liberdade do Relator em definir os participantes e as regras de interação entre os expositores - e seus possíveis usos e efeitos na decisão final da demanda.

Todos os atores direta ou indiretamente interessados na discussão podem pleitear a participação e o direito de fala mediante pedido fundamentado no processo que a originou, diretamente ao/à ministro/a relator/a responsável, que analisará a fundamentação para a participação na causa, aceitando ou recusando o pleito. Caberá ao/à ministro/a 
selecionar as pessoas que serão ouvidas, divulgar a lista dos habilitados, determinar a ordem dos trabalhos e fixar o tempo para a manifestação dos participantes.

Os expositores podem ser classificados de acordo com a origem da sua indicação, como: a) agentes estatais, indicados por um dos três poderes da República, ou pelo representante do Ministério Público; b) sociedade civil, sendo representantes de associações, entidades de classe, movimentos sociais, conselhos de políticas públicas ou associações voltadas para a defesa das causas em discussão; ou c) especialistas, que não representam uma posição oficial das instituições e entidades das quais fazem parte, mas dividem experiências e conhecimento do tema, como pesquisadores ou como ocupantes de cargos em instituições importantes da área. São ouvidos durante as audiências especialistas em questões técnicas, científicas, administrativas, políticas, econômicas e jurídicas, expondo seus argumentos no intuito de auxiliar os 150 votos dos/as ministros/as.

O objetivo das audiências públicas é, por meio de um mecanismo institucional jurídico, incluir uma dimensão social de participação e deliberação no controle de constitucionalidade. Este instrumento jurídico visa o debate público de matérias de grande importância social e que suscitam inúmeros questionamentos e entendimentos a respeito das questões discutidas. Essas informações contribuem para o conhecimento da matéria pelos/as ministros/as e para a incorporação de um maior teor de legitimidade social e democrática à decisão final, uma vez que a sociedade subsidia a Corte para uma tomada de decisão mais consciente e completa sobre a questão em análise.

A despeito da previsão de decisão individual do/a ministro/a relator/a na formação do quadro de participantes, a convocação de uma audiência pública busca garantir a presença de diferentes pontos de vista, interesses e valores mediante participantes diversificados. No tocante 
aos argumentos sustentados, há amplo espaço para a apresentação de posicionamentos de ordem técnica, histórica, relativa a valores, prática, distributiva, e até mesmo emocional. Também são aceitas evidências das mais diversas, como as técnico-científicas, as de autoridade, de testemunho, ou mesmo de senso comum. As sessões são organizadas em blocos, de acordo com o setor social do participante e com o posicionamento que este pretende defender, buscando o equilíbrio entre os diversos setores sociais e as posições diante do tema discutido.

Em nenhuma audiência pública foi permitido aos participantes dirigirem a palavra uns aos outros, sob o argumento de que se tratavam de audiências de caráter instrutório, e até mesmo as menções de um expositor à argumentação de outros eram reguladas. Ainda assim, verifica-se o intercâmbio indireto de ideias e a troca de informações pois, em geral, os envolvidos parecem já conhecer os principais argumentos uns dos outros e visam reforçá-los ou questioná-los com a apresentação de outros argumentos e evidências.

As audiências são transmitidas pela TV Justiça e pela Rádio Justiça e, no âmbito do Tribunal, o número de espectadores é limitado apenas pela capacidade do local de sua realização. As sessões também são transmitidas em tempo real na internet, sendo disponibilizadas no portal do STF as transcrições das falas ocorridas, bem como os demais comunicados e documentos que o/a ministro/a que preside a audiência entender relevantes para a publicidade da discussão.

Concluída a audiência pública e realizados os debates orais das partes no plenário do STF, os julgadores proferem seus posicionamentos e votos sobre a demanda discutida. Os argumentos levantados a favor e contra o pleito objeto de deliberação podem ser levados em consideração direta ou indiretamente nos votos dos/as ministros/as.

Contudo, tratando-se de uma prática institucional muito recente, há várias críticas à dinâmica das audiências públicas 
no STF. Primeiramente, o procedimento pode ser considerado parcialmente deliberativo, já que nem todos que pleiteiam espaço na audiência pública têm seu pleito deferido ${ }^{8}$, pois há análise e critérios de seleção prévios, sendo essa decisão do/a ministro/a irrecorrível. As arenas deliberativas também refletem as assimetrias de poder observadas na realidade, como o uso de linguagem excessivamente técnica, a intimidação por alguns participantes ocuparem posições institucionais de poder, e outros relativos a coerções e desigualdades no discurso público, fatos que demonstram uma necessidade de blindar estes espaços contra as assimetrias de poder e desigualdades de participação ${ }^{9}$ para que o potencial deliberativo seja maior.

Outra crítica é que, a despeito da abertura para a participação social diversificada, a consideração dos argumentos debatidos nas audiências e a decisão final sobre a demanda discutida cabem exclusivamente aos/às ministros/as da Corte. A participação social pode ser uma forma efetiva de influência, 152 mas o poder decisório permanece concentrado e não há qualquer obrigação por parte dos julgadores de enfrentar as questões debatidas ou as utilizar na fundamentação de seus votos.

Apesar das deficiências de um modelo ainda em aperfeiçoamento, os participantes do processo contribuem fornecendo informações diversificadas para a abordagem dos temas. $\mathrm{O}$ atual exemplo das audiências públicas no STF demonstra que no órgão mais alto do Judiciário há algum espaço para o aumento de sua "porosidade", para a inserção de pleitos sociais tematizados pelos próprios envolvidos e interessados na discussão, com a possibilidade de influência destes argumentos neste centro decisório e no debate público nacional sobre o tema em análise.

As audiências públicas, embora destinadas a esclarecer questões técnicas, administrativas, políticas, econômicas

\footnotetext{
8 Normalmente, por "falta de representatividade" ou por realizar o pedido fora do prazo estipulado pelo/a ministro/a relator/a do caso.

9 Sobre esse tema, ver Fraser (1992).
} 
e jurídicas, se tornaram, de acordo com o entendimento da Corte, um instrumento de legitimidade democrática, não tanto pelos argumentos manifestados, mas por propiciar a participação de atores que, de algum modo, representariam a sociedade na solução jurídica no controle da constitucionalidade, reduzindo o isolamento do Tribunal e promovendo sua aproximação com a sociedade civil, os movimentos sociais e a comunidade científica.

\section{Breve análise da audiência pública sobre cotas raciais}

A esfera pública jurídica pode ser concebida como um espaço aberto em uma área tradicionalmente pouco democrática, permitindo a participação de atores sociais que normalmente estariam fora do Judiciário e possuiriam pouco ou nenhum poder na deliberação sobre suas demandas por direitos. Uma esfera pública jurídica com intenções críticas e funções políticas ativas deve estar forte e intimamente conectada com o centro sistêmico, no sentido de que seus procedimentos influenciariam as decisões institucionais e alterariam a realidade jurídico-social, sendo esse o potencial emancipatório deste espaço.

Para demonstrar na realidade jurídica brasileira a existência e as características de um espaço institucional como o descrito, apresentamos uma breve análise da audiência pública sobre cotas étnico-raciais realizada no STF durante o julgamento da $\mathrm{ADPF} \mathrm{n}^{\mathrm{o}} 186^{10}$, que culminou no reconhecimento de políticas afirmativas pleiteadas por um grupo social historicamente marginalizado no Brasil, ao considerar constitucional a inserção das cotas raciais em processos seletivos para ingresso no ensino superior.

O motivo da escolha desta audiência pública específica é que nela encontramos uma luta histórica por direitos, sobre

\footnotetext{
10 A audiência pública está disponível na íntegra em vídeo (em: $<$ https://goo.gl/ HQAKfT >. Acesso em: 28 mar. 2018) e transcrita em nota taquigráfica (em: <https:// goo.gl/txSwhD>. Acesso em: 28 mar. 2018), assim como o acórdão final, também utilizado para a pesquisa (em: <https://goo.gl/rQZDL7>. Acesso em: 28 mar. 2018).
} 
questões estruturais do Brasil que levaram inevitavelmente à tematização de experiências de desrespeito, argumentos de reconhecimento e redistribuição e, principalmente, à discussão de que as desigualdades sociais brasileiras estariam diretamente conectadas com a existência de um racismo estruturante de nossa sociedade. Conforme a análise de Adilson José Moreira sobre o discurso jurídico e sua apropriação para legitimação de narrativas culturais:

Esses atores sociais formulam argumentos que articulam interpretações do princípio da igualdade, concepções de raça, definições de racismo, representações da nação brasileira e teorias sobre o papel do Estado. Embora esses temas sejam igualmente tratados pelas partes envolvidas, eles são associados a partir de perspectivas distintas, sendo que cada uma delas afirma que a interpretação por elas defendida melhor representa os interesses da Nação. Tendo em vista o fato de que os tribunais têm a última palavra na determinação dos sentidos das normas constitucionais, eles se tornaram no passado recente um espaço de batalhas entre posições favoráveis e contrárias à manutenção de certas hierarquias sociais. $\mathrm{O}$ aspecto político dessas controvérsias jurídicas nos convida a analisar decisões judiciais a partir de um ponto de vista diferenciado como sugerem autores ligados à tradição crítica do direito (Moreira, 2017, p. 832).

A ADPF $n^{0} 186$ foi ajuizada pelo partido Democratas (DEM), visando à declaração de inconstitucionalidade de alguns atos da Universidade de Brasília (UnB) que instituíram o sistema de reserva de vagas com base em critério étnico-racial ( $20 \%$ de cotas étnico-raciais) em seu processo de seleção para ingresso de estudantes.

Em síntese, as alegações para a inconstitucionalidade da política de ação afirmativa foram que: a) as cotas implementariam um "Estado racializado" no Brasil; b) a adoção 
de políticas afirmativas racialistas não seria necessária no Brasil; c) o conceito de minoria apta a ensejar uma ação afirmativa difere em cada país; d) no Brasil, ninguém é excluído apenas pelo fato de ser negro, e sim pela condição econômico-social; e) as cotas gerariam consciência estatal de raça, promoveriam ofensa arbitrária ao princípio da igualdade, gerando discriminação reversa em relação aos brancos pobres, além de favorecerem a classe média negra; f) teria sido institucionalizado, na $\mathrm{UnB}$, um verdadeiro tribunal racial para definir quem é negro e quem não é, questionando os critérios utilizados para esse fim; e g) não se pode responsabilizar as gerações presentes por erros cometidos no passado, e seria impossível identificar os legítimos beneficiários dos programas de natureza compensatória.

A questão fundamental examinada pela Corte e debatida na audiência pública foi definir se os programas de ação afirmativa que estabelecem um sistema de reserva de vagas com base em critério étnico-racial para acesso ao ensino superior estariam ou não em consonância com a Constituição Federal.

Na audiência pública, ocorrida nos períodos da manhã e da tarde dos dias 3 a 5 de março de 2010, além das partes interessadas e de alguns dos/as ministros/as do STF, participaram representantes de órgãos públicos, especialistas em educação, direitos humanos e sociologia, representantes de universidades públicas estaduais e federais e das diversas organizações da sociedade civil que atuam na temática de questões raciais ${ }^{11}$. O ministro Ricardo Lewandowski, relator da $\mathrm{ADPF} \mathrm{n}^{\circ}$ 186, habilitou 43 participantes para argumentar. No primeiro dia, foi dado a palavra às instituições estatais responsáveis pela regulação e organização das políticas nacionais de educação e de combate à discriminação étnica

11 Programação completa e lista dos participantes disponíveis em: $<$ https://goo. gl/PyZMgG >. Acesso em: 28 mar. 2018. 
e racial, bem como ao Instituto de Pesquisas Aplicadas (IPEA). No segundo dia, houve a argumentação entre os defensores da tese da constitucionalidade e da inconstitucionalidade das políticas de reserva de vagas para o acesso do ensino superior, com cinco representantes de cada posição. No último dia, ocorreu a continuidade do contraditório e apresentação das experiências das universidades públicas relativas à aplicação das políticas de ação afirmativa destinadas a ampliar o acesso de estudantes ao ensino superior.

Passamos à análise das argumentações dos participantes da audiência pública, focando nos argumentos levantados pelos representantes de movimentos sociais ligados à questões étni$\operatorname{cas}^{12}$. Interessante notar que algumas entidades optaram por escolher seus representantes entre profissionais e acadêmicos simpatizantes e com atuação ligada às questões étnico-raciais, sendo esses os mais indicados para traduzir suas demandas e se aproximar da questão jurídica debatida, mesmo com suas falas 156 não tratando estritamente de argumentos jurídicos ou técnicos, tematizando também experiências de desrespeito ligadas à questão debatida e ao movimento que representaram.

Nessas argumentações, menciona-se diversas vezes que a desigualdade social está diretamente ligada a um racismo que é estruturante da sociedade brasileira e, por esse motivo, as políticas de ações afirmativas estariam em consonância com a Constituição no que tange a redução das desigualdades sociais, a não discriminação e a promoção da igualdade.

Essa argumentação nos parece se ligar diretamente a uma luta por reconhecimento de um direito à igualdade material, como é possível depreender da fala de José Vicente, presidente da Afrobras e reitor da faculdade Zumbi dos Palmares:

12 Principalmente nas falas dos representantes do Centro de Estudos Africanos da USP, Afrobras, Educafro, Fundação Cultural Palmares, Ação Educativa, Coordenação Nacional de Entidades Negras (Conen), Movimento Negro Socialista, Instituto da Mulher Negra de São Paulo: Geledés, Movimento-Pardo Mestiço Brasileiro e da Associação dos Caboclos e Ribeirinhos da Amazônia, e do Movimento contra o desvirtuamento do espírito da reserva das cotas sociais. 
O caso dos negros brasileiros, Excelência, é um caso evidente, profundo e angular de desigualdade estrutural. Foram mais de trezentos anos de escravidão sem qualquer tipo de reparação. Por quase quatro séculos, homens, mulheres e crianças negras foram sequestradas, subjugadas, seviciadas, torturadas e assassinadas em praças públicas, com a complacência e indiferenças das muitas instituições sociais do nosso país, naquela época, com a omissão e mesmo participação do Estado, e no mais das vezes com o beneplácito da própria Justiça (Brasil, 2010, pp. 251-252).

Sustentou-se também que, no Brasil, o preconceito está ligado com a aparência dos sujeitos e que a abolição da escravidão deixou um legado de desigualdade para a posteridade, sendo que os números sobre educação, trabalho e renda da população negra comparada com os brancos demonstram essa ligação.

Para fundamentar a desigualdade alegada, os participantes também invocaram dados socioeconômicos da população, demonstrando a necessidade do reconhecimento do racismo estrutural, argumento sustentado, por exemplo, pelo professor Fábio Konder Comparato, representante da Educafro:

No mercado de trabalho, com a mesma qualificação e escolaridade, negros e pardos recebem, em média, quase a metade dos salários pagos aos brancos. Em nossas cidades, mais de dois terços dos jovens assassinados entre quinze $\mathrm{e}$ dezoito anos são negros. No ensino médio, 58,4\% (cinquenta e oito vírgula quatro por cento) dos alunos são brancos, e $37,4 \%$ (trinta e sete vírgula quatro por cento) são negros - no ensino médio -, mas no ensino superior essa desigualdade é escandalosa. Na Universidade de São Paulo, a maior universidade do Brasil, temos menos de $2 \%$ (dois por cento) de alunos negros (BRASIL, 2010, p. 268). [...] a adoção das cotas raciais está em plena harmonia, compatibilidade, 
consonância com a ordem internacional e com a ordem constitucional. As cotas são o imperativo democrático a louvar o valor da diversidade. São imperativos de justiça social a aliviar a carga de um passado discriminatório e a fomentar transformações sociais necessárias. Devem prevalecer as cotas em detrimento desse suposto direito à perpetuação das desigualdades estruturais que tanto comprometem a sociedade brasileira (Brasil, 2010, p. 277).

Argumento semelhante também é sustentado na fala da representante do Instituto da Mulher Negra de São Paulo Geledés, doutora Sueli Carneiro:

Os que vislumbram o futuro acreditam que se as condições históricas nos conduziram a um país em que a cor da pele ou a racialidade das pessoas tornou-se fator gerador de desigualdades, essas condições não estão inscritas no DNA nacional, pois são produto da ação ou inação de seres humanos e, por isso mesmo, podem ser transformadas, intencionalmente, pela ação dos seres humanos de hoje (Brasil, 2010, pp. 304-305).

Esse argumento que consideramos central - de que, no Brasil, as desigualdades raciais estão conectadas intrinsecamente com a desigualdade socioeconômica - foi repetido por diversos participantes a favor das cotas, enfrentado no acórdão da decisão final (Brasil, 2012) e um dos fundamentos para a decisão de constitucionalidade dessa política de ação afirmativa, como demonstra a fala de Denise Carreira, representante da Ação Educativa:

Em decorrência de todo esse quadro e da dimensão do problema caracterizado por desigualdades e discriminações raciais da educação básica à educação superior, entendemos que o Estado brasileiro, em busca de justiça 
social, deve avançar com relação ao enfrentamento do racismo como questão estruturante da educação brasileira (Brasil, 2010, p. 284).

Da mesma forma, Marco Antônio Cardoso, representante da Coordenação Nacional de Entidades Negras, sustenta:

a nossa luta pelas ações afirmativas e por cotas raciais no Brasil tem uma perspectiva de futuro, porque para nós o racismo não escolhe tempo, nem espaço, nem lugar. $\mathrm{O}$ racismo é mais que uma ideologia, é uma instituição em si, constituída na História. O racismo se realimenta, se retroalimenta cotidianamente, pois se reforça no apoio incondicional das elites econômicas, movidas que são pelos seus privilégios e pelo que o eurocentrismo legou à ciência e ao mercado. As doutrinas eurocêntricas influenciaram, além de formar parte significativa dos intelectuais brasileiros, influenciaram, sim, as instituições do Estado e as instituições privadas, e sobretudo as instituições educacionais. [...] nós do movimento negro brasileiro sabemos que explicitar o racismo e, porventura, os conflitos étnicos e raciais, é necessário e fundamental para evidenciar a desigualdade entre campos de poder e romper com a cristalização e a naturalização das desigualdades raciais na sociedade brasileira (Brasil, 2010, p. 289).

Alguns dos participantes também referenciaram argumentos dos defensores da inconstitucionalidade das cotas que defenderam a inexistência de racismo no Brasil, e que a desigualdade seria puramente econômica, declarando que essas afirmações desqualificariam a experiência de vida das pessoas discriminadas, negando a sua realidade vivida.

No debate, também se considerou a recuperação da identidade racial como fator importante para a emancipação 
através do reconhecimento jurídico, medida esta que pode ser efetiva para o "empoderamento", tanto psicológico como social e material, das minorias (Honneth, 2009). Outro argumento levantado foi o resultado das políticas de ações afirmativas para a criação de lideranças em grupos discriminados, capazes de lutar pela defesa de seus direitos, além de servirem como paradigmas de integração e ascensão social.

Além disso, algumas falas salientaram a importância do ganho em publicidade e relevância do tema no debate público para que se forme uma consciência pública da questão, já que as decisões dos temas de significativo interesse nacional necessitam de apoio público e de divulgação dos argumentos.

Por meio desta breve análise das falas da audiência pública, observamos que o pleito pelo direito foi ligado a uma desigualdade social estruturante da sociedade brasileira. A demanda por reconhecimento de direito à igualdade material foi sustentada pela demonstração do racismo estrutural, 160 fundamentando a constitucionalidade das cotas étnico-raciais como forma de justiça redistributiva. Como observa Adilson José Moreira sobre o tema e o julgamento do caso:

a decisão que afirmou a constitucionalidade de cotas raciais em instituições de ensino superior segue uma interpretação da igualdade de caráter progressista que contém muitos elementos de uma teoria chamada de antissubordinação. Ela afirma o compromisso com a justiça substantiva e a compreensão da igualdade como um mecanismo de emancipação social. De forma similar aos tribunais inferiores que apoiaram medidas racialmente inclusivas, a decisão afirmou que o atual paradigma constitucional contém uma concepção transformadora da igualdade. [...] O princípio da igualdade material tem importância instrumental para o alcance desse objetivo porque impõe uma obrigação ao Estado de eliminar as disparidades entre grupos raciais. A ação afirmativa tem o potencial de 
atingir o objetivo de promover os ideais de emancipação consagrados na Constituição Brasileira, pois esses programas tentam corrigir injustiças históricas. Na oferta de educação e de oportunidades profissionais para afrodescendentes e ameríndios, essas iniciativas materializam a cidadania entre grupos raciais no Brasil (Moreira, 2017, p. 861).

Ao analisar esta audiência pública específica, observa-se a importância da tradução de temas tradicionalmente não jurídicos para a forma jurídica e, no caso estudado, para a discussão sobre questões estruturantes em nossa sociedade. Segundo o professor Boaventura de Sousa Santos sobre a relação entre teoria e prática das lutas sociais:

Em vez de uma teoria que unifique a variedade imensa de lutas e movimentos, do que precisamos é de uma teoria da tradução - ou seja, uma teoria que, mais do que tentar criar outra realidade (teórica) por sobre os movimentos e à margem deles, procure promover entre eles uma compreensão mútua, uma inteligibilidade mútua, para que todos eles possam beneficiar das experiências dos demais e com eles colaborar. Os procedimentos da tradução dispensam as nossas descrições rarefeitas, baseando-se antes em descrições espessas. Na verdade, a especificidade dos relatos de dois ou mais movimentos ou lutas nunca é tanta que garanta uma tradução não-problemática entre elas (Santos, 2003, p. 33).

Ainda conforme Santos, o direito pode alterar as estruturas de poder, assim como também tornar mais rígidas as trocas entre poderes e reproduzir a exclusão. O caso interpretado a partir da filosofia habermasiana pode pontuar a contribuição do direito para a igualdade nas relações de poder, visando reduzir a exclusão social ou elevando a possibilidade e a qualidade da inclusão e da luta política 
pela democratização da possibilidade de coordenar os fins sociais, e consequentemente diminuir o monopólio estatal sobre tal coordenação - em outras palavras, a luta reflete em um pleito por desenhos institucionais alternativos, e o direito pode ser utilizado como um recurso para fins emancipatórios (2003).

Portanto, nosso principal objetivo foi demonstrar a importância e o potencial de influência da argumentação de atores sociais envolvidos na causa em discussão em um centro decisório jurídico aberto para recebê-los. Observa-se também a importância da tematização de questões tradicionalmente "não jurídicas" traduzidas para a forma jurídica e, no caso estudado, para a discussão sobre a constitucionalidade de uma ação afirmativa. Um Judiciário considerado democrático deve ser aberto aos atores sociais e ter instrumentos para traduzir razões do mundo da vida para o código do direito, aprofundando a conexão entre as institui162 ções e a realidade social.

\section{Conclusão}

Buscamos demonstrar neste artigo que a construção teórica sobre as características do espaço das audiências públicas do STF ligado ao referencial teórico habermasiano da esfera pública jurídica indicam o funcionamento deste novo mecanismo institucional, permitindo a troca de energias sociais tradicionalmente ausentes em uma arena jurídica como o STF.

Segundo Marcos Nobre, para Habermas, o procedimento é o formato do processo em questão - que seria “capaz de permitir o surgimento do maior número possível de vozes, de alternativas de ação e de formas de vida, garantindo seu direito de expressão e de participação" (2008, p. 18), e que não teria conteúdo definido e nem poderia ser guiado por concepções já determinadas; sua forma é apenas regulamentada. 
A deliberação democrática indica "quem" deve participar e "como", mas não "qual" seria o preenchimento correto dos conteúdos, sobre "o que" deve ser decidido. Os procedimentos de audiências públicas não fornecem nenhuma orientação e nem garantem o "conteúdo" das deliberações e como estas podem afetar as decisões. A importância central não recai sobre a pauta debatida, tanto no sentido do tema (cotas, aborto, drogas ilícitas, saúde pública, questões ambientais etc.) como no sentido dos tipos de argumentos utilizados pelos participantes (históricos, científicos, jurídicos etc.), mas sim no mais importante, o próprio procedimento democrático e seu potencial de responder à altura das demandas sociais.

Nas audiências públicas, as deliberações podem ser consideradas exemplos de formação democrática da vontade no interior de uma arena formal e de que há, em alguma medida, uma esfera pública jurídica aberta e atuante em intermediar as demandas sociais e as decisões dos centros formais, permitindo aos mais diversos atores sociais tradicionalmente localizados às margens dos sistemas decisórios utilizá-la para ampliar e/ou efetivar direitos.

A análise dessas experiências particulares é fundamental para compreender a extensão da legitimidade democrática do Judiciário, sendo que não basta apenas observar o potencial emancipatório do direito ou definir princípios de justiça abstratos; é preciso observar as instituições e procedimentos existentes a fim de diagnosticar e compreender quais práticas podem ser consideradas democráticas e que possuem potencial de aumentar a participação social mediante as audiências públicas e a "porosidade" do Judiciário para captar seus pleitos.

Apesar da construção teórica, o elemento mais importante deste trabalho se constitui pelas pessoas que lutam por direitos. A energia social produzida por experiências de desrespeito, por injustiça e pela organização de movimentos 
sociais em esferas públicas informais possui potencial emancipatório quando há espaço para se infiltrar nos centros de decisão. Esses procedimentos são significativos aos grupos e indivíduos socialmente marginalizados, que nunca tiveram voz nas instituições para discutir suas próprias experiências e as maneiras que acreditam ser justas para sanar esses problemas, visando uma mudança social efetiva.

\section{Ricardo Juozepavicius Gonçalves}

é doutorando em Filosofia e Teoria Geral do Direito pela Faculdade de Direito da Universidade de São Paulo (2018). Mestre em Filosofia e Teoria Geral do Direito pela mesma instituição (2017), com estágio de pesquisa na Freie Universität Berlin (Lateinamerika-Institut). Advogado inscrito na $\mathrm{OAB} / \mathrm{SP}$ e graduado em Direito pela Faculdade de Direito de São Bernardo do Campo (2013). Exerce estágio docente na Faculdade de Direito da Universidade de São

164 Paulo, na disciplina de Introdução ao Estudo do Direito.

\section{Bibliografia}

AVRITZER, Leonardo; COSTA, Sérgio. 2004. Teoria crítica, democracia e esfera pública. Dados: Revista de Ciências Sociais, Rio de Janeiro, v. 47, n. 4 , pp. $703-728$.

BRASIL. Supremo Tribunal Federal. 2010. Arguição de descumprimento de preceito fundamental 186: recurso extraordinário 597.285. Brasília, DF: STF. Disponível em: <https://goo.gl/txSwhD>. Acesso em: 28 mar. 2018. . Supremo Tribunal Federal. 2012. Acórdão da arguição de descumprimento de preceito fundamental 186. Brasília, DF: STF. Disponível em: <https://goo.gl/rQZDL7>. Acesso em: 28 mar. 2018.

COSTA, Sérgio. 1994. Esfera pública, redescoberta da sociedade civil e movimento sociais no Brasil: uma abordagem tentativa. Novos Estudos Cebrap, São Paulo, n. 38, pp. 38-52.

FRASER, Nancy. 1992. Rethinking the public sphere. In: CALHOUN, Craig (ed.). Habermas and the public sphere. Cambridge, MA: MIT Press, pp. 109-142.

FRASER, Nancy; HONNETH, Axel. 2003. Redistribution or recognition? a political-philosophical exchange. London: Verso. 
GONÇALVES, Ricardo Juozepavicius. 2017. O conceito de esfera pública jurídica entre Jürgen Habermas e Axel Honneth. 117 f. Dissertação de Mestrado em Direito. São Paulo: USP.

HABERMAS, Jürgen. 1984. The theory of communicative action. Boston: Beacon, 2 v. 1997. Direito e democracia. Rio de Janeiro: Tempo Brasileiro, 2 v. 2002. A luta por reconhecimento no Estado democrático de direito. In: . A inclusão do outro. São Paulo: Loyola, pp. 229-267. 2014. Mudança estrutural da esfera pública. São Paulo: Unesp.

HONNETH, Axel. 2009. Luta por reconhecimento: a gramática moral dos conflitos sociais. São Paulo: Editora 34.

LUBENOW, Jorge Adriano. 2012. A categoria da esfera pública em Jürgen Habermas: para uma reconstrução da autocrítica. João Pessoa: Manufatura.

MARONA, Marjorie Corrêa; ROCHA, Marta Mendes. 2014. As audiências públicas do Supremo Tribunal Federal: ampliando sua legitimidade democrática? Teoria e Sociedade, Belo Horizonte, v. 22, n. 1, pp. 53-86.

MELO, Rúrion. 2015. Repensando a esfera pública: esboço de uma teoria crítica da democracia. Lua Nova, São Paulo, n. 94, pp. 11-39.

MOREIRA, Adilson José. 2017. Direito, poder, ideologia: discurso jurídico como narrativa cultural. Direito E̊ Práxis, Rio de Janeiro, v. 8, n. 2, pp. 830-868.

NEVES, Raphael; LUBENOW, Jorge Adriano. 2008. Entre promessas e desenganos: lutas sociais, esfera pública e direito. In: NOBRE, Marcos; TERRA, Ricardo (orgs.). Direito e democracia: um guia de leitura de Habermas. São Paulo: Malheiros, pp. 249-267.

NOBRE, Marcos. 2008. Introdução. In: NOBRE, Marcos; TERRA, Ricardo (orgs.). Direito e democracia: um guia de leitura de Habermas. São Paulo: Malheiros, pp. 15-35.

REPA, Luís Sérgio. 2008. Direito e teoria da ação comunicativa. In:

NOBRE, Marcos; TERRA, Ricardo (orgs.). Direito e democracia: um guia de leitura de Habermas. São Paulo: Malheiros, pp. 55-71.

RODRIGUEZ, José Rodrigo. 2006. O direito liberal para além de si mesmo:

Franz Neumann, o direito e a teoria crítica. $181 \mathrm{f}$. Tese de Doutorado em Filosofia. Campinas: Unicamp. 2013a. Como decidem as cortes? para uma crítica do direito (brasileiro). Rio de Janeiro: FGV.

SANTOS, Boaventura de Souza. 2003. Poderá o direito ser emancipatório? Revista Crítica de Ciências Sociais, Coimbra, n. 65, pp. 3-76.

2011. Para uma revolução democrática da justiça. 3. ed. São Paulo: Cortez. 
SILVA, Felipe Gonçalves. 2011. Entre potenciais e bloqueios comunicativos: Habermas e a crítica do Estado democrático de direito. Caderno CRH, Salvador, v. 24, n. 62, pp. 307-330. 2013. Habermas e ambiguidade do direito moderno. In: SILVA, Felipe Gonçalves; RODRIGUEZ, José Rodrigo (coords.). Manual de sociologia jurídica. São Paulo: Saraiva, pp. 134-153.

VOIROL, Olivier. 2008. A esfera pública e as lutas por reconhecimento: de Habermas a Honneth. Cadernos de Filosofia Alemã: Crítica e Modernidade, São Paulo, n. 11, pp. 33-56. 


\section{O CONCEITO DE ESFERA PÚBLICA JURÍDICA E A}

\section{AUDIÊNCIA PÚBLICA SOBRE COTAS RACIAIS NO SUPREMO TRIBUNAL FEDERAL}

\section{RICARDO JUOZEPAVICIUS GONÇALVES}

Resumo: O objetivo deste artigo é apresentar o conceito de esfera pública jurídica nas produções de Jürgen Habermas e exemplificá-lo através do mecanismo institucional das audiências públicas do Supremo Tribunal Federal, tratando, ao final, da audiência sobre a constitucionalidade das cotas raciais para ingresso no ensino superior. Apresentamos o conceito habermasiano buscando explicar uma arena institucional com um diferente potencial democrático deliberativo no interior do Judiciário, bem como melhor compreender as trocas de energia social que podem influenciar posicionamentos nos centros decisórios jurisdicionais.

Palavras-chave: Teoria Crítica; Jürgen Habermas; Esfera Pública Jurídica; Audiências Públicas; Cotas Raciais.

\section{THE CONCEPT OF LEGAL PUBLIC SPHERE AND THE PUBLIC HEARING ON RACIAL QUOTAS WITHIN THE SUPREME COURT}

Abstract: The purpose of this paper is to present the concept of legal public sphere in Jürgen Habermas' work, exemplifying it through the institutional mechanism of public hearings that occur within the Brazilian Supreme Court, ultimately discussing the public hearing on the constitutionality of racial quotas for admission to higher education. We present this Habermasian concept seeking to explain an institutional arena with a different deliberative democratic potential within the Judiciary, as well as to better understand the social energy exchanges that can influence positionings in judicial decision-making centers. 
Resumos $\mid$ Abstracts

Keywords: Critical Theory; Jürgen Habermas; Legal Public Sphere; Public Hearings; Racial Quotas.

Recebido: 08/02/2018 Aprovado: 23/03/2018 